\title{
IMPLICAÇÕES GEOLÓGICAS E TECTÔNICAS DA INTERPRETAÇÃO MAGNETOMÉTRICA DA REGIÃO DE OLIVEIRA, MINAS GERAIS
}

\author{
Maurício Antônio Carneiro ${ }^{1}$ e Maria Sílvia Carvalho Barbosa² \\ Recebido em 19 março, 2007 / Aceito em 12 março, 2008 \\ Received on March 19, 2007 / Accepted on March 12, 2008
}

\begin{abstract}
This work presents the interpretation of magnetometric data obtained from Oliveira region (1:100,000 scale), located into the southern portion of the São Francisco Craton (Minas Gerais, Brazil). The geology of this region encompasses Archean igneous and metamorphic rocks of the Campo Belo Metamorphic Complex, (Archean and Proterozoic) supracrustal sequences and a Proterozoic mafic dike swarm. Due to advanced weathering, the region lacks rock outcrops and in this particular case magnetometry plays an important role. Thus, the interpretation of geophysical data allowed the characterization of five major structural lineament families, named $\mathrm{L}$, M, N, 0 and P, at the regional sialic substrate. Field Geologic mapping confirmed these lineaments which are predominantly related to two (gabbronoritic and gabbroic) mafic dike families, metaultramafites, iron formations and faults.
\end{abstract}

Keywords: magnetometry, Southern São Francisco Craton, Minas Gerais.

RESUMO. Apresenta-se neste trabalho o resultado do processamento dos dados aeromagnetométricos da região de Oliveira (escala 1:100.000), situada na porção meridional do Cráton São Francisco, em Minas Gerais. A geologia dessa folha compreende rochas ígneas e metamórficas arqueanas, atribuídas ao Complexo Metamórfico Campo Belo, sequiências supracrustais (arqueanas e proterozóicas) e um enxame de diques máficos do Proterozóico. Em função de seu avançado manto intempérico a região carece de afloramentos rochosos e, nesse particular, a magnetometria auxilia o mapeamento geológico. A interpretação realizada permitiu a caracterização de 5 grandes famílias de lineamentos estruturais, ora denominados de L, M, N, 0 e P, existentes no substrato siálico regional. 0 mapeamento geológico, realizado a seguir, reconheceu que os lineamentos no campo estão relacionados, predominantemente, a duas famílias de diques máficos (gabronoríticos e gabróicos), metaultramafitos, formações ferríferas e falhas.

Palavras-chave: magnetometria, Cráton São Francisco Meridional, Minas Gerais.

\footnotetext{
${ }^{1}$ Departamento de Geologia, Escola de Minas, Universidade Federal de Ouro Preto, Campus Universitário, Morro do Cruzeiro s/n, 35400-000 Ouro Preto, MG, Brasil. Tel.: (31) 3559-1882; Fax (31) 3559-1600 - E-mail: mauricio@degeo.ufop.br

${ }^{2}$ Departamento de Geologia, Escola de Minas, Universidade Federal de Ouro Preto, Campus Universitário, Morro do Cruzeiro s/n, 35400-000 Ouro Preto, MG, Brasil. Tel.: (31) 3559-1890; Fax (31) 3559-1600 - E-mail: silvia@degeo.ufop.br
} 


\section{INTRODUÇÃo}

Nos últimos anos, o avanço das técnicas de interpretação geofísica, através dos métodos magnetométrico e gamaespectrométrico, tem auxiliado o mapeamento geológico, principalmente em regiões onde a cobertura de solo é espessa e os afloramentos são escassos (e.g. Blum et al., 2001; Silva et al., 2003; Teixeira et al., 2006). Esse é o caso, por exemplo, da folha topográfica Oliveira (escala 1:100.000; IBGE) situada na região centro sul do estado de Minas Gerais, limitada pelos paralelos $20^{\circ} 30^{\prime} S-21^{\circ} 00^{\prime} S$

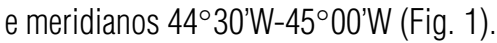

A magnetometria, ferramenta utilizada neste trabalho, consiste na medição de pequenas variações do campo magnético terrestre em conseqüência da distribuição heterogênea das rochas magnetizadas. Com isso, é possível delimitar os principais lineamentos e fontes com minerais ferromagnéticos, aflorantes ou subaflorantes. Em continuidade ao processamento dos dados aeromagnetométricos, foi realizado um levantamento geológico no campo, para aferir a natureza tectônica dos lineamentos diagnosticados pela aerogeofísica e, conseqüentemente, aferir a sua constituição geológica. Nesse sentido, apresenta-se, neste trabalho, o resultado do processamento dos dados aeromagnetométricos da folha Oliveira, destacando os seus principais lineamentos magnetométricos e uma cronologia tentativa dos eventos tectônicos que afetaram essa região.

\section{CONTEXTO GEOLÓGICO}

Em termos geotectônicos a folha Oliveira está situada na porção meridional do Cráton São Francisco (Fig. 2). Esse cráton faz parte da plataforma pré-cambriana (Almeida, 1977; Alkmim et al., 1993), que engloba grande parte dos territórios dos estados de Minas Gerais e Bahia. A porção meridional desse cráton é um segmento crustal siálico de evolução policíclica, tectonicamente estável em relação aos cinturões móveis do ciclo Brasiliano (Alkmim et al., 1993) e apresenta uma significante exposição de terrenos granito-greenstone neoarqueanos com evolução tectônica iniciada no Mesoarqueano (Teixeira et al., 1996a, 1998, 2000; Carneiro et al., 1998a).

De maneira geral, o segmento crustal siálico do Cráton São Francisco Meridional, no domínio da folha Oliveira, é constituído, predominantemente, por gnaisses, granitóides, anfibolitos, rochas máficas, ultramáficas e charnoquitos, que foram agrupados, regionalmente, por Machado Filho et al. (1983), nos complexos metamórficos Divinópolis e Barbacena. Localmente, esses autores caracterizaram seqüências supracrustais (e.g. quartzitos, xistos e ultramafitos) que foram correlacionadas aos supergrupos
Rio das Velhas ou Minas. No entanto, Teixeira et al. (1996a) agruparam os complexos metamórficos Divinópolis e Barbacena em uma única unidade, que foi denominada Complexo Metamórfico Campo Belo (CMCB), cuja evolução geológica teria início no Mesoarqueano. Pesquisas geológicas realizadas nessa região têm possibilitado a caracterização de unidades litodêmicas no CMCB e, portanto, contribuído para compor um modelo tectônico mais acurado acerca da evolução geológica da porção meridional do Cráton São Francisco (Campos, 2004; Campos et al., 2003; Carneiro et al., 1996a, 1996b, 1997a, 1997b, 1997c, 1998a, 1998b, 2006; Carvalho Jr., 2001; Carvalho Jr. et al., 1997, 1998; Fernandes, 2001; Fernandes \& Carneiro, 2000; Fernandes et al., 1997, 1998; Costa, 1999; Costa et al., 1998, 2006; Oliveira, 1999, 2004; Oliveira \& Carneiro, 1999, 2001; Oliveira et al., 1998a, 1998b, 1999). Nesse sentido, de acordo com Carneiro et al. (2006), a porção setentrional da folha Oliveira é constituída, predominantemente, pelo gnaisse Cláudio, seguido pelos gnaisses Candeias e Itapecerica. No quadrante noroeste da folha ocorrem três faixas estreitas de uma seqüência supracrustal (e.g. metaultramafitos, xistos, quartzitos e formação ferrífera bandada) correlacionável ao Supergrupo Rio das Velhas (Oliveira, 1999, 2004). Na porção meridional da folha Oliveira, de leste a oeste da folha, ocorre 0 gnaisse Fernão Dias. Nesse gnaisse intrudem os granitóides Rio do Amparo e Bom Sucesso. Já o quadrante sudeste da folha é marcado por uma estreita faixa supracrustal (e.g. xistos, quartzitos e formação ferrífera) correlacionável ao Supergrupo Minas (Machado Filho et al., 1983). Nesse quadrante também ocorrem 0 granitóide Tabuões e 0 gnaisse São Tiago. Além dessas unidades maiores, ocorrem afloramentos esparsos de mafitos diversos (gabros, gabronoritos e anfibolitos) e metaultramafitos. Esses últimos podem ser correlacionados à Seqüência Acamadada Ribeirão dos Motas (Carneiro et al., 1996a; Carvalho Jr., 2001; Carneiro et al., em preparação). 0 acervo geocronológico dessa região pode ser encontrado em Teixeira (1985, 1993), Teixeira et al. (1996a, 1996b, 1997, 1998, 2000), Campos (2004) e Oliveira (2004) que, também, propuseram um modelo de evolução crustal caracterizado por sucessivas etapas de acresção/diferenciação associadas a processos de retrabalhamento crustal (Teixeira, 1993; Teixeira \& Canzian, 1994; Teixeira et al., 1987, 1996a, 1996b, 1997, 1998, 1999, 2000; Carneiro et al., 1996b, 1997a, 1997b, 1998a, 1998b; Pinese, 1997; Noce et al., 2000; Campos, 2004; Oliveira, 2004). 0 ápice desses processos ocorreu no Neoarqueano, durante o Evento Tectonotermal Rio das Velhas (Carneiro et al., 1998a). Mas no Mesoarqueano ocorreram dois eventos de natureza tectonotermal e um evento de migmatização (e.g. 3,2 ga; 2,9 ga e 2,86 ga; Teixeira et al., 

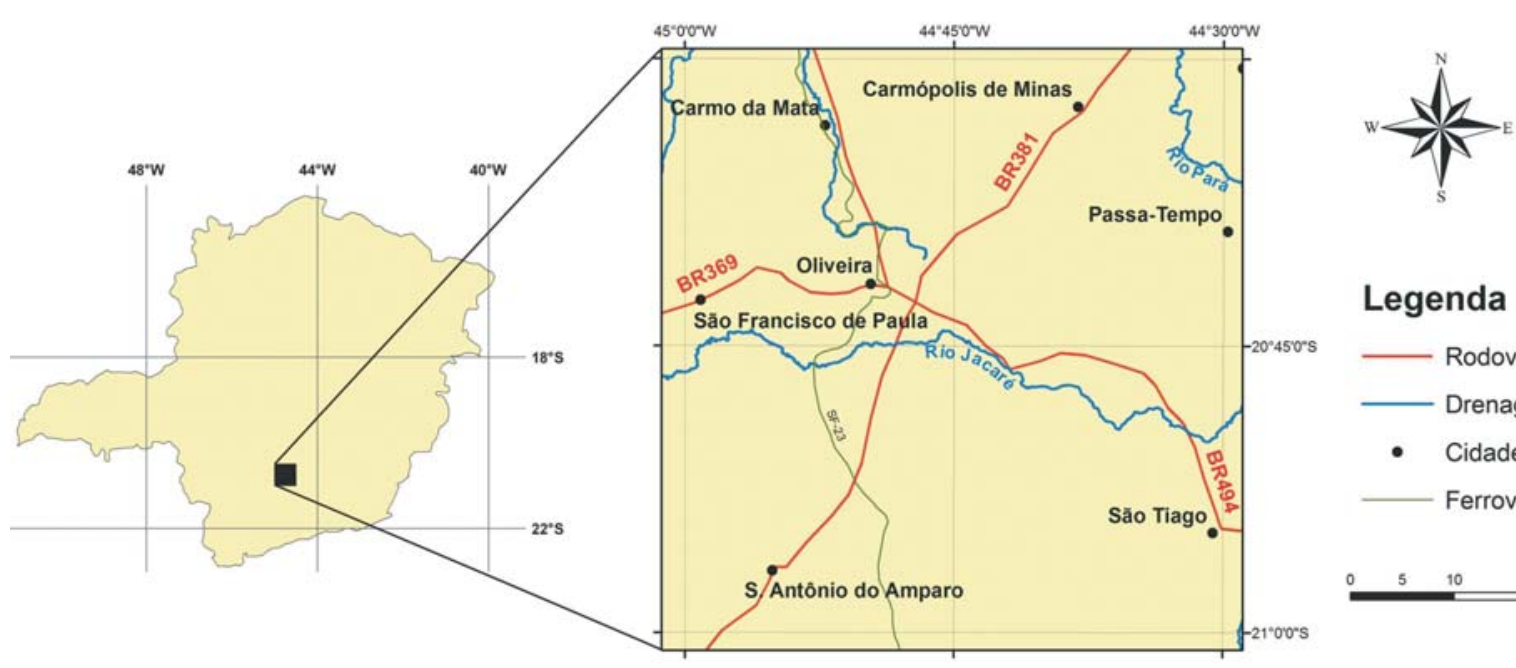

\section{Legenda}

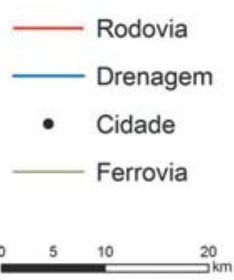

Figura 1 - Mapa de localização da folha topográfica Oliveira (escala 1:100.000, IBGE)

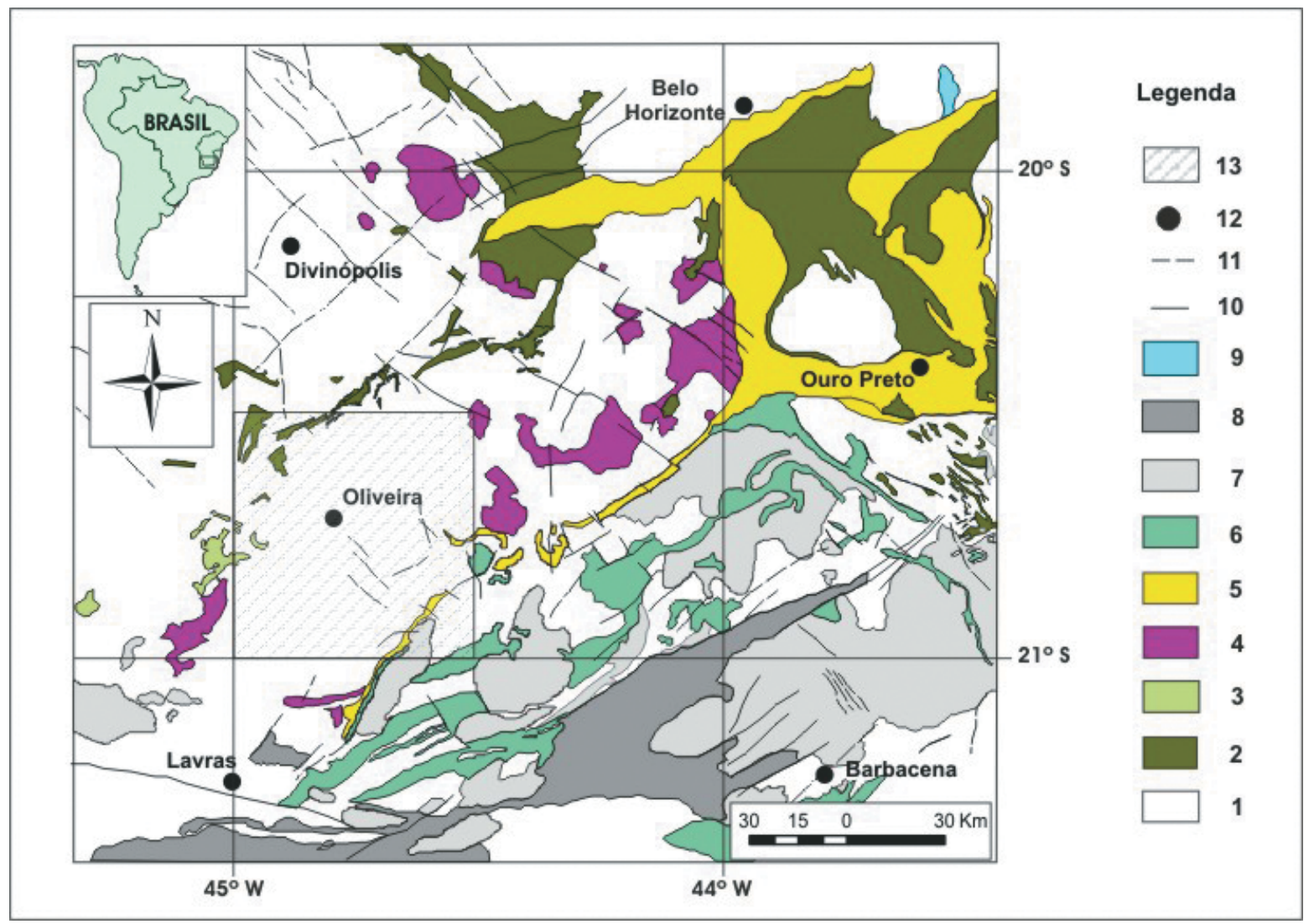

Figura 2 - Geologia (simplificada) da porção meridional do Cráton São Francisco e adjacências (Modificado de Campos, 2004). Simbologia: 1 - Complexos metamórficos indiferenciados; 2 - Seqüências supracrustais arqueanas do tipo greenstone belt; 3 - Metaultramafitos do tipo Seqüência Acamadada Ribeirão dos Motas; 4 - Granitóides neoarqueanos; 5 - Supergrupo Minas; 6 - Seqüências supracrustais paleoproterozóicas do tipo greenstone belt; 7 - Granitóides paleoproterozóicos; 8 - Seqüências supracrustais paleoproterozóicas indiferenciadas; 9 - Seqüências supracrustais paleo- mesoproterozóicas de natureza pelítica; 10 - Contatos geológicos; 11 - Lineamentos e falhas; 12 - Cidades; 13 - Área correspondente à folha Oliveira (paralelos 20º'S- $21^{\circ} 00^{\prime}$; ; meridianos $44^{\circ} 30^{\prime} \mathrm{W}-45^{\circ} 00^{\prime} \mathrm{W}$ ). 
1996a, 1998, 2000; Noce, 1995) e um evento de magmatismo félsico também teve lugar no Neoarqueano (2,65 ga, Noce, 1995). No Proterozóico ocorreram dois eventos de magmatismo máfico fissural (Pinese, 1997; Oliveira, 2004) e um evento de alto grau metamórfico com magmatismo charnockítico associado (Oliveira, 2004). Devido a essa sucessão de eventos, a relação tectônica entre as unidades geradas (ou retrabalhadas) foi progressivamente mascarada. Assim sendo, um registro tectono-estrutural bastante complexo foi impresso nas unidades litodêmicas que constituem o CMCB, nas seqüências supracrustais e nos corpos intrusivos que constituem o substrato siálico regional. Nesse contexto evolutivo, com relação às variedades gnáissicas encontradas na foIha Oliveira, o gnaisse Fernão Dias tem, indiscutivelmente, idade mesoarqueana (Teixeira et al., 1996a, 1998, 2000). Os demais, a exceção do gnaisse São Tiago, têm idade incerta mas podem ter protólitos arqueanos retrabalhados no Proterozóico. Já o gnaisse São Tiago deve ter uma idade, essencialmente, proterozóica, assim como o granitóide Tabuões. Já os granitóides Rio do Amparo e Bom Sucesso são neoarqueanos (Carneiro et al., 2006).

\section{MATERIAIS E MÉTODOS}

Os dados aeromagnetométricos pré-processados, utilizados neste trabalho, são de propriedade da CODEMIG (Companhia de Desenvolvimento Econômico de Minas Gerais) e foram cedidos para finalidades acadêmicas ao Degeo/EM/UFOP. Para a aquisição dos dados aeromagnetométricos (Lasa, 2001), foi utilizado um magnetômetro com sensor de vapor de césio (bombeamento óptico) com resolução de $10^{-3} \mathrm{nT}$. As leituras do magnetômetro foram realizadas em intervalos de $0,1 \mathrm{~s}$, equivalentes a uma medida a cada 5,5 m. Para controle diário das variações do campo magnético foi utilizado um magnetômetro terrestre de resolução de $10^{-3} \mathrm{nT}$, realizando leituras do campo geomagnético em intervalos de $1 \mathrm{~s}$. Para backup do sistema de monitoração da variação diurna foi utilizado um magnetômetro de resolução de 0,01 nT, coletando dados a cada $3 \mathrm{~s}$ (Lasa, 2001). Os parâmetros que nortearam a execução desse levantamento são: linhas de vôo na direção N3OW, espaçamento entre as linhas de vôo de $250 \mathrm{~m}$, direção das linhas de controle N60E, espaçamento entre as linhas de controle $2.500 \mathrm{~m}$, altura média de vôo $100 \mathrm{~m}$, velocidade aproximada de vôo de $200 \mathrm{~km} / \mathrm{h}$ e sistema de navegação GPS Picodas/ NovAtel/Racal (Lasa, 2001).

A partir dos dados cedidos pela CODEMIG, o processamento dos dados consistiu de uma série de etapas (Fig. 3). 0 arquivo ASCII foi importado para 0 software OASIS MONTAJ 5.0 (sistema GEOSOFT S.A.) gerando o arquivo .gdb. Através da rotina WINXY do software supracitado, processou-se os dados de forma a utilizar apenas os dados da área em estudo. Os dados do campo magnético anômalo, corrigido do IGRF (International Geomagnetic Reference Field) foram interpolados, através de mínima curvatura, em uma malha regular de $300 \mathrm{~m}$. Em seguida, realizouse 0 micronivelamento nos dados com o objetivo de homogeneizar a representação espectral espacial do campo magnético (Minty, 1991). Após as correções, geraram-se os mapas: Campo Magnético Anômalo (reduzido do IGRF), Gradiente Vertical (ou primeira derivada vertical em "Z"), Campo Residual; Gradientes Horizontais (direções EW; ou em Y e NS; ou em X), Amplitude do Sinal Analítico (ASA) e Gradiente Vertical da Amplitude do Sinal Analítico (DASA). Utilizando o "software ArcGis (versão 9.0)", os sete mapas magnetométricos georreferenciados foram integrados no ambiente GIS para cartografia dos principais lineamentos estruturais da folha Oliveira.

\section{DISCUSSÃO DOS RESULTADOS}

0 mapa do campo magnético anômalo (Fig. 4) da folha Oliveira, com a remoção do IGRF, apresenta uma predominância de, pelos menos, duas famílias de lineamentos contínuos e bem marcados magnetometricamente, na direção NW-SE e, muito subordinadamente, alguns lineamentos nas direções NE e ENE.

A primeira família dos lineamentos NW-SE tem direção aproximada de N50-60W e, a segunda, tem a direção N30W, sendo que, essa segunda, aparentemente desloca a primeira, mas ambas seccionam os lineamentos NE e ENE e que ocorrem nos quadrantes SE e NW da folha Oliveira, respectivamente. Observase, no entanto, que as rochas com maior magnetização (ou com maior presença de materiais ferromagnéticos), se concentram na porção S da área (Fig. 4), onde configuram uma grande unidade magnetométrica distribuída na direção NE-SW. Contudo, afloram nessa região, predominantemente, litotipos félsicos pertencentes aos gnaisses Fernão Dias e São Tiago e aos granitóides Rio do Amparo, Bom Sucesso e Tabuões. Usualmente essas rochas têm baixa magnetização. Rochas com alta magnetização, como é 0 caso de metaultramafitos, também ocorrem nessa região mas os seus afloramentos estão restritos a uma pequena faixa no quadrante SW da folha, correspondendo às anomalias mais baixas. Este fato se deve ao posicionamento da área no hemisfério sul do globo terrestre. A porção setentrional da folha Oliveira, por sua vez, especialmente 0 quadrante NE, se caracteriza por apresentar terrenos com baixa magnetização. No entanto, essa região, à semelhança da região meridional, é constituída por litotipos gnáissicos (gnaisses Cláudio, Itapecerica e Candeias). Mas, 0 


\begin{tabular}{|c|c|c|c|c|c|}
\hline vL176:0 & $\mathrm{x}$ & $\mathrm{Y}$ & Mag_corr & & \\
\hline 554.0 & 529562.50 & 7675875.00 & 0.38662 & & \\
\hline 555.0 & 529625.00 & 7675875.00 & 0.38120 & & \\
\hline
\end{tabular}

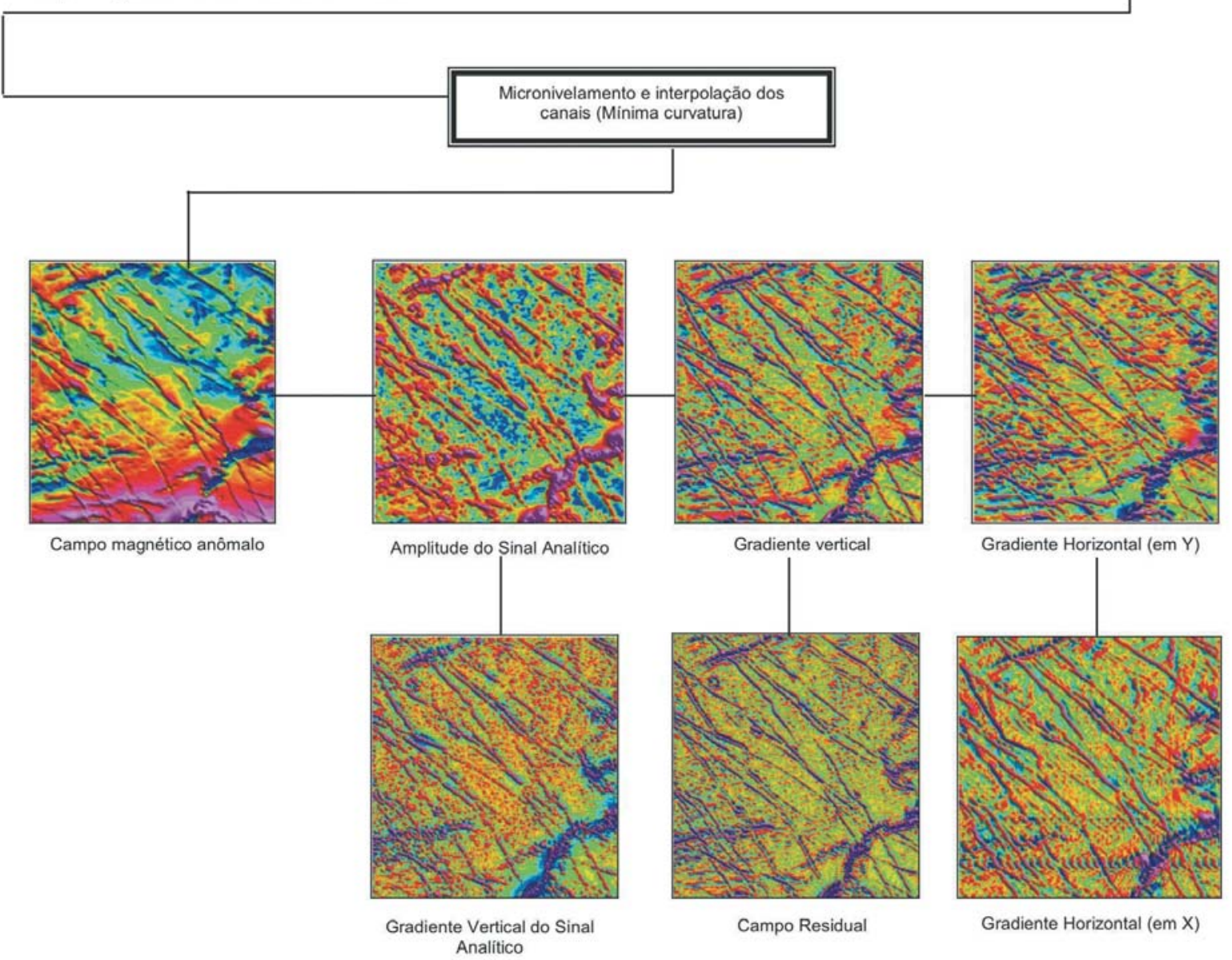

Figura 3 - Fluxograma das etapas de processamento dos dados aeromagnetométricos da folha Oliveira.

levantamento geológico de campo mostrou que, em parte do quadrante NE, ocorrem metaultramafitos que são, usualmente, portadores de alta magnetização. A Figura 5 mostra 0 gradiente vertical do campo magnético anômalo da folha Oliveira. Como se sabe, os filtros aplicados nos mapas magnetométricos de gradiente vertical são apropriados para realçar fontes rasas sem alterar a polaridade das anomalias magnéticas.

De modo geral, os resultados obtidos nesse tipo de tratamento mostram uma boa correspondência com os mapeamentos geológicos de superfície. No caso da folha Oliveira (Fig. 5) observa-se que os lineamentos diagnosticados na Figura 4, especialmente aqueles das duas famílias NW-SE permanecem nítidos e os litotipos mais magnetométricos parecem aflorar ou estar muito próximos à superfície. Nesse sentido, no decorrer do levantamento geológico de campo, em vários locais situados ao longo desses lineamentos, foram encontrados litotipos ora gabróicos ora gabronoríticos. Por outro lado, a julgar pelas considerações de Costa (1999), Costa et al. (2006) a família de lineamentos $\mathrm{N} 50^{\circ}-60^{\circ} \mathrm{W}$ (Sistema Lençóis 1) é constituída, predominantemente, por diques máficos da composição gabronorítica ao passo que a família de lineamentos segundo a direção $\mathrm{N} 35^{\circ}-45^{\circ} \mathrm{W}$ (Sistema Lençóis 2) exibe, predominantemente, litotipos gabróicos. Esses autores também descrevem na região de Campo Belo, a oeste da folha Oliveira, que os diques gabronoríticos são cortados 


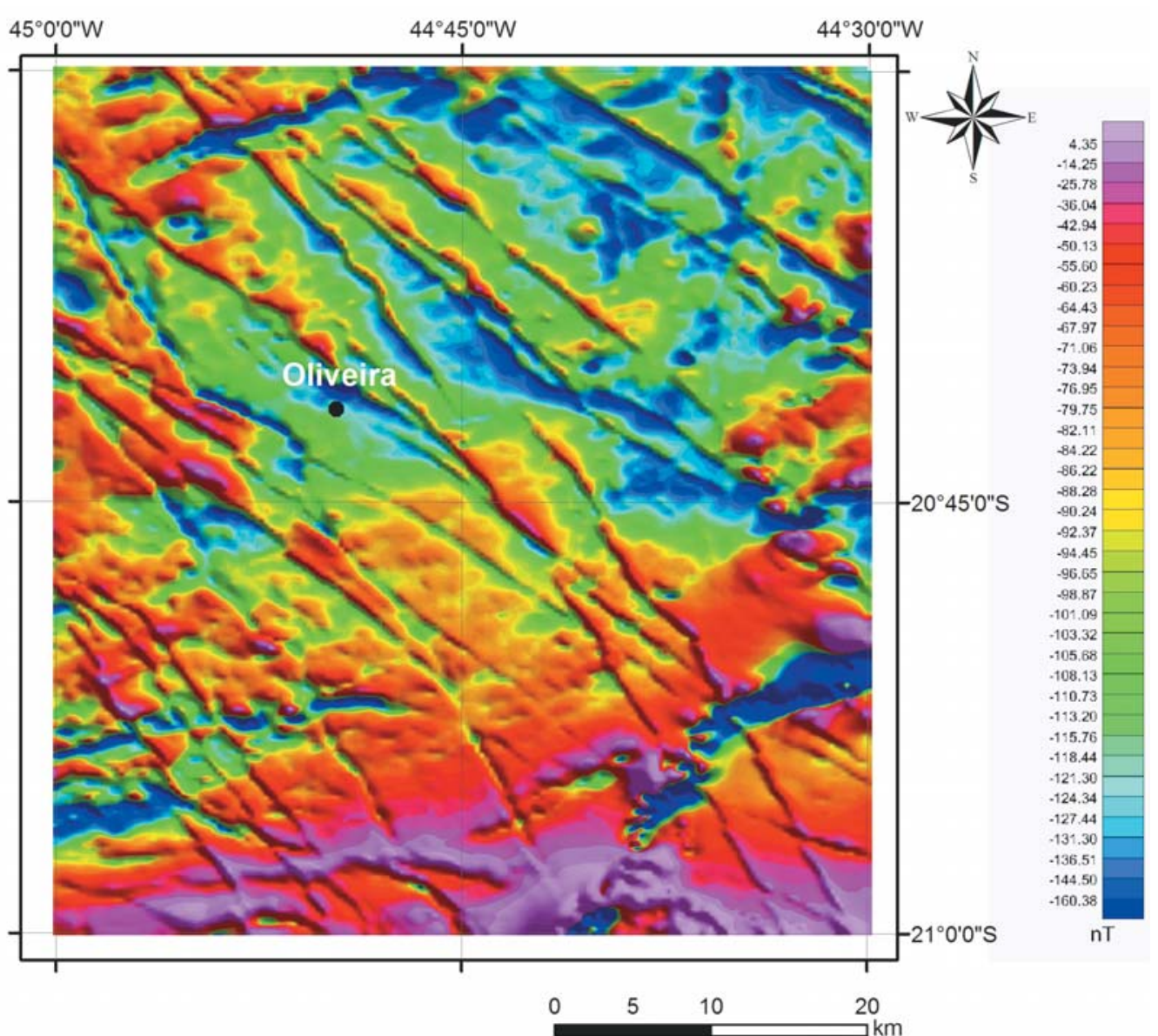

Figura 4 - Campo magnético anômalo (retirado o IGRF) na folha Oliveira.

pelos diques gabróicos. Na região de Cláudio, ao norte da folha Oliveira, Oliveira (2004) e Carneiro \& Oliveira (2005) obtiveram idades radiométricas ${ }^{40} \mathrm{Ar}{ }^{39} \mathrm{Ar}$ contrastantes para esses diques, de modo que aqueles de composição gabronorítica são mais antigos e foram posicionados na crosta por volta de 1,7 Ma. Já os diques gabróicos são mais jovens e teriam uma idade em torno de 1,0 Ma. Entretanto, as rochas de maior magnetização, que caracterizavam uma vasta região situada na porção meridional da folha Oliveira, e claramente visualizada no mapa do campo magnético anômalo (Fig. 4), perde representatividade na Figura 5. Como as rochas aflorantes nessa região possuem baixa magnetização (gnaisses e granitóides quartzo-feldspáticos) conclui-se, então, que os litotipos responsáveis por essa anomalia estão posicionados em níveis mais profundos da crosta. Por outro lado, os lineamentos NEE e NE, situados respectivamente nos quadrantes NW e SE, são constituídos, predominantemente, por seqüências supracrustais (e.g. xistos, quartzitos, etc., com intercalações de formação ferrífera). 0 lineamento NE que ocorre no quadrante SE da folha Oliveira, por sua vez, foi interpretado por Campos (2004) como uma zona de cisalhamento transcorrente sinistral (Zona de Cisalhamento Jeceaba-Bom Sucesso) que separa o bloco siálico NW, essencialmente arqueano, do bloco siálico, essencialmente paleoproterozóico, situado a SE desse lineamento.

A Figura 6 exibe 0 mapa da amplitude do sinal analítico (ASA), que é uma função simétrica, em formato de sino, com 0 seu máximo sobre o topo de cada contato geológico e sua largura está diretamente relacionada com a profundidade do corpo. Assim, o ASA é utilizada para localizar as profundidades dos contatos magnéticos e projetar o corpo na superfície.

As características dipolares do campo magnético anômalo dificultam a interpretação magnetométrica. Uma saída é transformá-lo em monopolar através da redução ao pólo. No entanto, essa redução não foi realizada porque, em situações de baixas latitudes $\left(\theta<25^{\circ}\right)$ e de provável campo remanescente (e.g. terrenos 


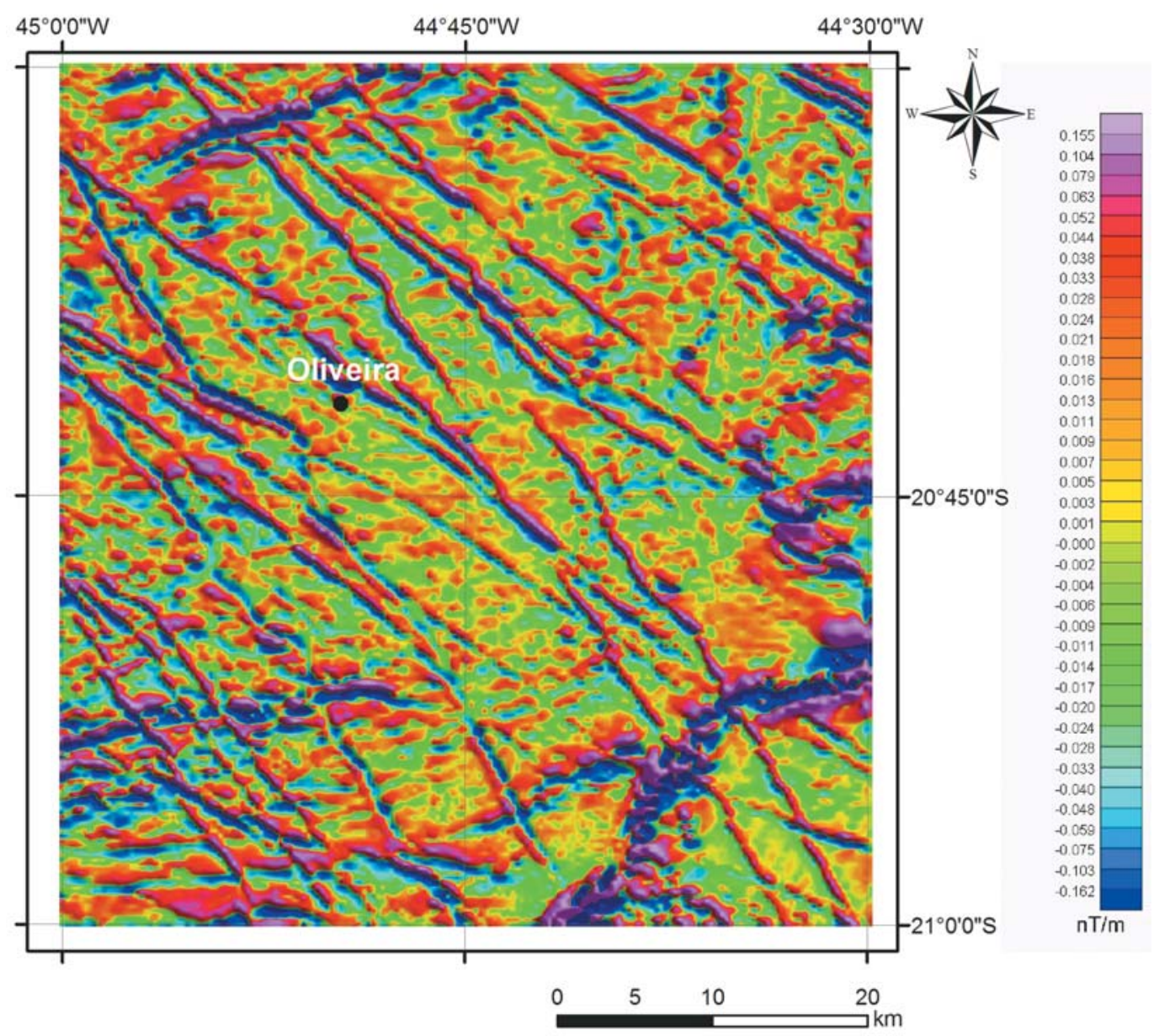

Figura 5 - Gradiente vertical do campo magnético anômalo (CMA) na folha Oliveira.

antigos, de grande residência crustal) ela não deve ser aplicada (e.g. Swain, 1976). Para contornar esse problema, de acordo Fairhead \& Maus (2003) utilizou-se a derivada vertical da amplitude do sinal analítico obtendo-se, assim, separações eficientes das anomalias causadas por estruturas que estão muito próximas (Fig. 7).

\section{CONCLUSÃO}

Da discussão anterior, fica claro que os lineamentos e ou anomalias magnetométricas da folha Oliveira estão imersos num substrato rochoso com magnetização moderada e uniforme, comportando-se como um "pano de fundo" (Fig. 8).

Esse substrato apresenta concentrações de Fe aparentemente homogêneas e constitui 0 embasamento rochoso regional formado por gnaisses e granitóides, arqueanos e paleoproterozóicos. Sobre esse embasamento estão dispostas as seqüências supracrustais (arqueanas e proterozóicas) e intrusivo nele, as rochas metaultramáficas e os diques máficos. Esses corpos são as fontes das anomalias que emergem do substrato e, na Figura 8 , estão designadas pelas letras L, M, N, 0 e P. Assim, as fontes de anomalia L, que se localizam nos quadrantes SE, NW e, também, no centro leste da folha de Oliveira correspondem, respectivamente, a uma estreita faixa do Supergrupo Minas, possuidora de uma camada de formação ferrífera. No quadrante NW a anomalia $L$ corresponde a uma estreita faixa do Supergrupo Rio das Velhas que tem metaultramafitos associados. Já na parte centro leste essa anomalia corresponde a uma faixa estreita de metaultramafitos, correlacionável a Seqüência Acamadada Ribeirão dos Motas. Observa-se ainda, que as fontes da anomalia L, na porção SE da folha Oliveira, são as que contêm a maior concentração de ferro, apresentam a maior magnetização registrada na área e correspondem a uma formação ferrífera, de idade proterozóica. No quadrante SW aparece uma família de anomalias designada pela letra M, com direção aproximadamente EW. 


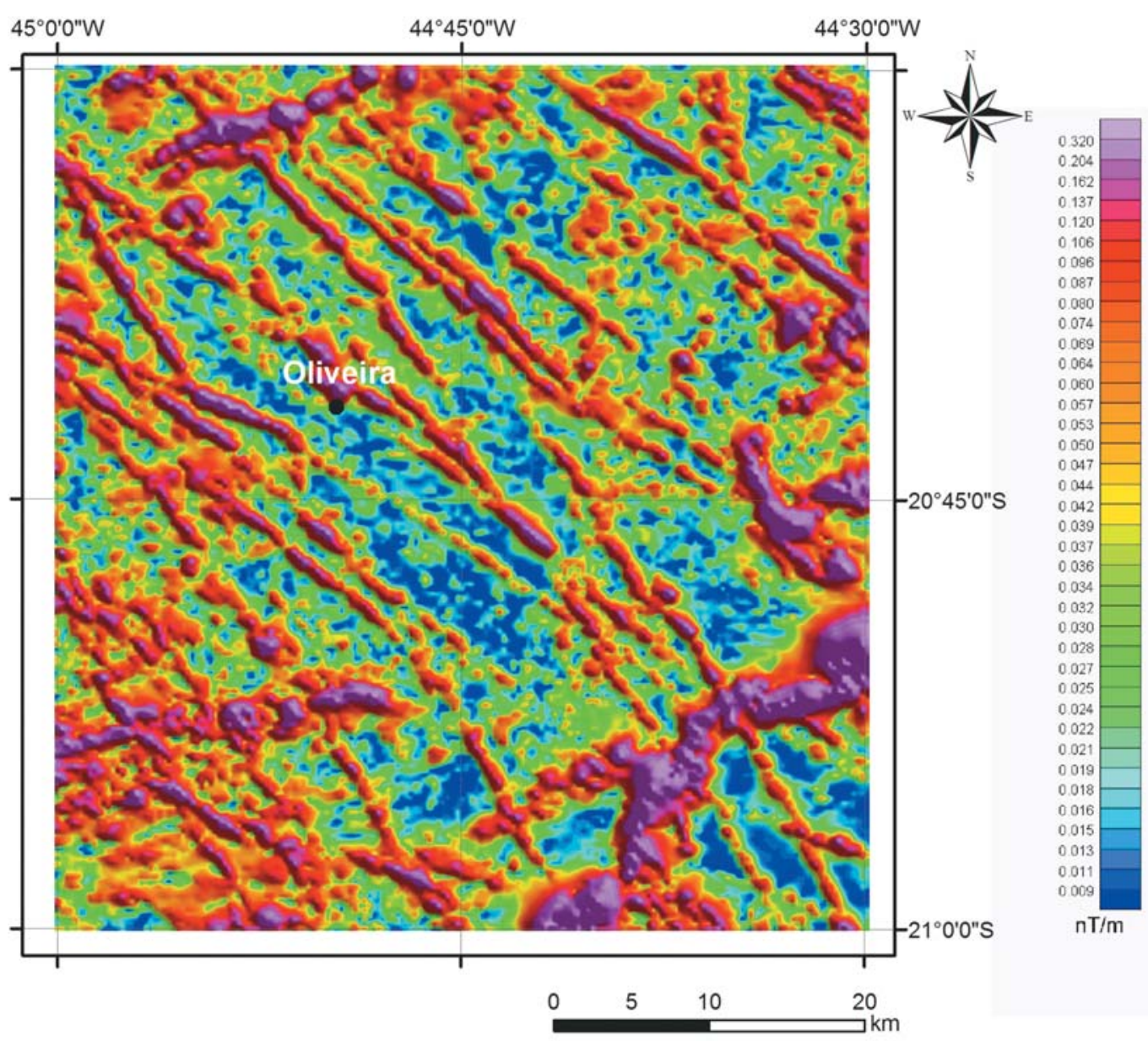

Figura 6 - Amplitude do sinal analítico da folha Oliveira.

No entanto, nessa área predominam rochas granitóides e gnáissicas e, portanto, a natureza dessa anomalia é desconhecida em superfície. Já as estruturas N, com direção NW-SE, estão concentradas, principalmente, nos quadrantes SW e NW e correspondem aos diques gabronoríticos. Cortando os lineamentos $\mathrm{L}, \mathrm{M}$ e N tem-se, em grande concentração, a presença dos lineamentos 0 , alinhados também na direção NW-SE, com o teor de ferro superior ao substrato rochoso mas inferior às concentrações de existentes nos lineamentos L, M e N. Os lineamentos 0 correspondem aos diques gabróicos. Ressalta-se, ainda, que ao analisar o mapa de magnetização anômala e seus derivados (Figs. 4 a 7) percebe-se que 0 padrão de dipolaridade do campo magnético atual (positiva ao norte e negativa ao sul) não é observado em toda área. Existem anomalias com o padrão oposto (positiva ao sul e negativa ao norte) evidenciando rochas com remanescência magnética e direção de magnetização oposta ao campo magnético atual. Assim, com base na direção de magnetização reversa, definem- se dois grupos de diques de eventos distintos (lineamentos $\mathrm{Ne}$ 0 , Fig. 8). Assim, as anomalias aqui denominadas de $L, M, N$ e $P$ têm direção de magnetização atual, enquanto a anomalia 0 (diques gabróicos) possuem magnetização reversa. Finalmente, os lineamentos $\mathrm{P}$, localizados no quadrante NE da folha Oliveira correspondem à falhas geológicas do tipo transcorrente com movimento destral, conforme observado no mapeamento geológico (Carneiro et al., 2006).

\section{AGRADECIMENTOS}

Esse trabalho foi possível pelo apoio de várias entidades e pessoas. Nesse particular, agradecemos especialmente a CODEMIG pela cessão dos dados magnetométricos, CPRM pelo apoio logístico, FAPEMIG (projetos CRA 2205-02, 619-04-03, 203205), CNPq (Grant para MAC) e os bolsistas de iniciação científica do LOPAG/DEGEO/EM/UFOP. 


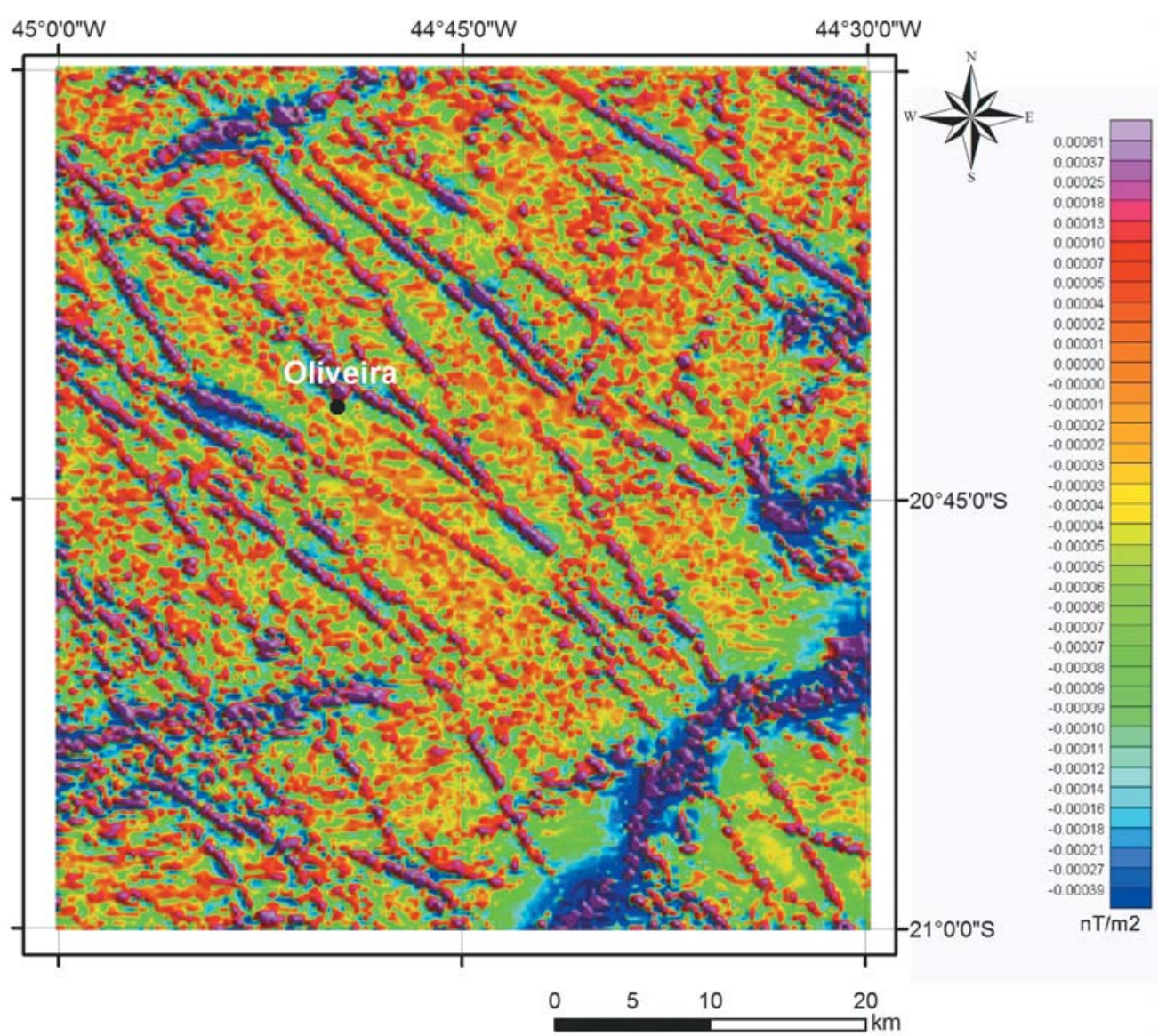

Figura 7 - Gradiente vertical da amplitude do sinal analítico da folha Oliveira.

\section{REFERÊNCIAS}

ALKMIM FF, NEVES BBB \& ALVES JAC. 1993. Arcabouço tectônico do Cráton do São Francisco - Uma revisão. In: DOMINGUEZ JML \& MISI A (Ed.). 0 Cráton do São Francisco. Salvador, SBG-NBA/SE, SGM, CNPq. p. 45-62.

ALMEIDA FFM. 1977. 0 Cráton do São Francisco. Revista Brasileira de Geociências, 7: 349-364.

BLUM MLB, SILVA AM, JOST H, MENESES PR, FUCK RA, BROD JA, TEIXEIRA AA, SILVA AAC, SPIGOLON ALD, MAAS MVR, SOUZA MM, MACEDO Jr P, LIMA BEM \& CAMPOS MO. 2001. Aplicação de dados aerogeofísicos no mapeamento geológico do limite entre os terrenos Arqueanos e Proterozóicos da região de Crixás-Cedrolina, Goiás. Revista Brasileira de Geociências, 31(3): 279-286.

CAMPOS JCS. 2004. 0 lineamento Jeceaba-Bom Sucesso como limite dos terrenos arqueanos e paleoproterozóicos do Cráton São Francisco Meridional: evidências geológicas, geoquímicas (Rocha Total) e geocronológicas (U-Pb). Tese de Doutorado. DEGEO/EM/UFOP. 190 p.

CAMPOS JCS, CARNEIRO MA \& BASEI MAS. 2003. U-Pb evidence for
Late Neoarchean crustal reworking in the southern São Francisco Craton (Minas Gerais, Brazil). Anais da Academia Brasileira de Ciências, 75 : 497-511.

CARNEIRO MA \& OLIVEIRA AH de. 2005. Tectonic evolution of Southern São Francisco Craton: Three Tectonothermal events based on ${ }^{40} \mathrm{Ar} /{ }^{39} \mathrm{Ar}$ isotopic data. In: Simpósio sobre o Cráton do São Francisco, III: 2005. Salvador. Anais. .. Salvador: SBG. p. 200-203.

CARNEIRO MA, TEIXEIRA W, NALINI Jr HA, BILAL E, OLIVEIRA AH \& CARVALHO Jr IM. 1996a. Archean ultramafic-mafic magmatism in the Southern São Francisco Craton (Campo Belo Complex): Preliminary petrographic and geochemical results. In: Symp. Archean Terranes of the South American Platform, I: 1996. Brasília. Anais. . Brasilia: SBG. p. 32-33.

CARNEIRO MA, TEIXEIRA W, NOCE CM \& FERNANDES RA. 1996b. Archean growth processes in the Quadrilátero Ferrífero: A geochronological U-Pb and Sm-Nd approach to the Rio das Velhas Event (2780-2700 Ma). In: Symp. Archean Terranes of the South American Platform, I: 1996. Brasília. Anais. . Brasília: SBG. p. 59-60. 


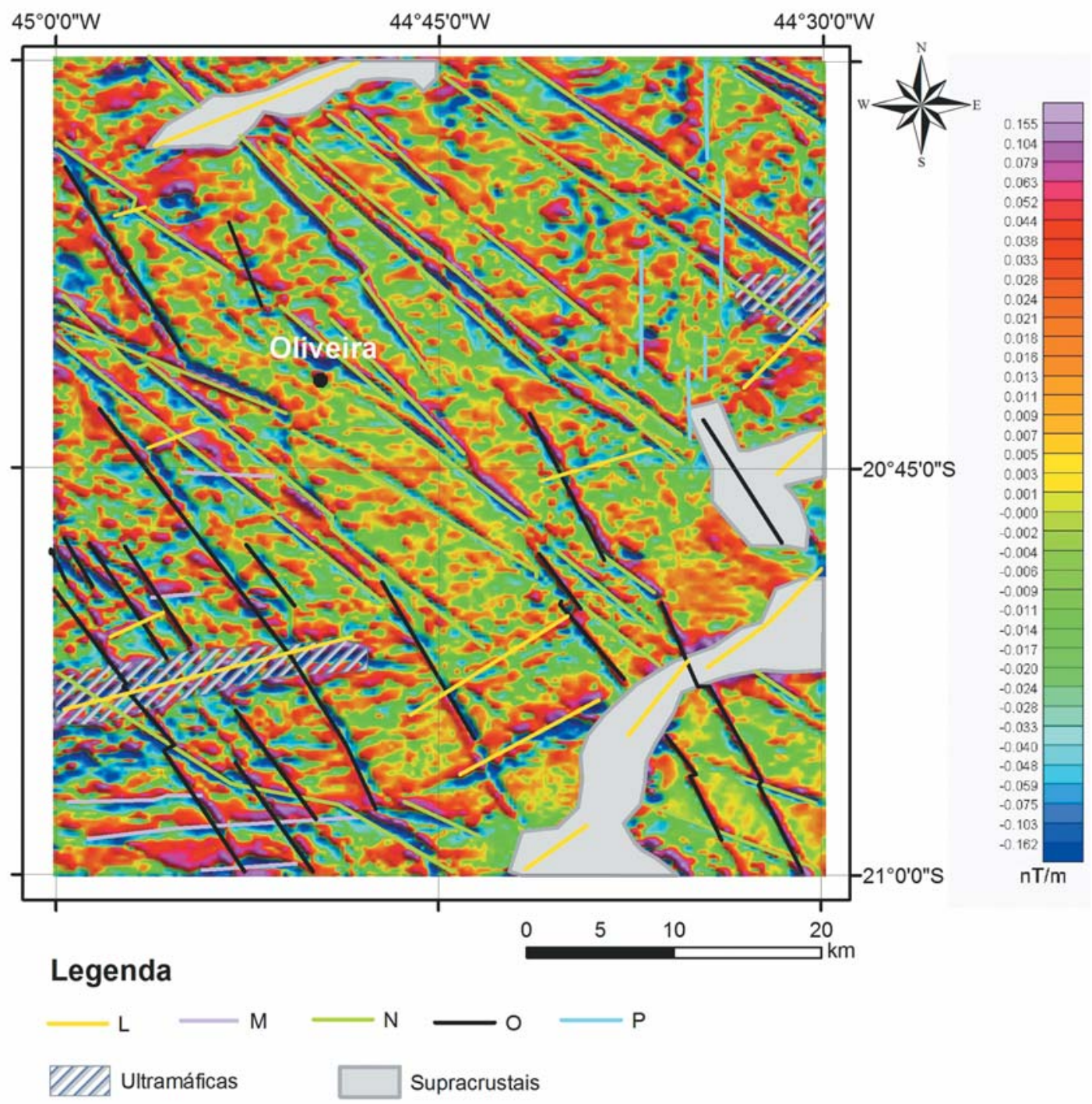

Figura 8 - Gradiente vertical do campo magnético anômalo da folha Oliveira com interpretação sobreposta.

CARNEIRO MA, CARVALHO Jr IM, FERNANDES RA \& TEIXEIRA W. 1997a. Geologia de parte do segmento crustal situado entre as cidades de Oliveira, Campo Belo e Santana do Jacaré, MG. In: Simp. Geol. de Minas Gerais, IX: 1997. Ouro Preto. Anais. . . Ouro Preto: SBG. 14: 36-37.

CARNEIRO MA, NALINI Jr HA, BILAL E, CARVALHO Jr IM, TEIXEIRA W \& MOUTTE J. 1997b. A seqüência Acamadada de Ribeirão dos Motas, Minas Gerais, Brasil. In: Sem. Geoq. X, Cong. Geoq. Países de Língua Portuguesa IV: 1997. Braga. Actas. . Braga: SBG. p. 31-33.

CARNEIRO MA, TEIXEIRA W, CARVALHO Jr IM, OLIVEIRA AH \& FERNANDES RA. 1997c. Archean Sm/Nd isochron age from the Ribeirão dos Motas layered rocks sequence, Southern São Francisco Craton, Brazil. In: South-American Symp. on Isotope Geology, I: 1997. Campos do
Jordão. Extended Abstracts. . . Campos do Jordão: SBG. p. 63-64.

CARNEIRO MA, TEIXEIRA W, CARVALHO Jr IM \& FERNANDES RA. 1998a. Sialic crust as a part of the Archean greenstone belt basement, evidence from the Bonfim Metamorphic Complex, Quadrilátero Ferrífero, Brazil. Revista Brasileira de Geociências, 28: 71-82.

CARNEIRO MA, CARVALHO Jr IM \& TEIXEIRA W. 1998b. Petrologia, Geoquímica e Geocronologia dos Diques Máficos do Complexo Metamórfico Bonfim Setentrional (Quadrilátero Ferrífero) e suas Implicações na Evolução Crustal do Cráton do São Francisco Meridional. Revista Brasileira de Geociências, 28: 29-44.

CARNEIRO MA, NALINI Jr HA, ENDO I, SUITA MTF, CASTRO PTA, BARBOSA MSC, CAMPOS JCS, GOULART LEA, SILVA EF, PEREIRA AA, TAVARES TD, JIAMELARO F, CARNEIRO JM, MARIANO LC, MIGUEL 
FP, SILVA Jr AC, BARBOSA AS, PRADO GEA, SANTOS C \& URBANO EEMC. 2006. Mapas Geológicos das Folhas Campo Belo e Oliveira. Escala 1:100.000. Programa Geologia do Brasil. Convênio UFOP-CPRM. Relatório Final. 192 p.

CARNEIRO MA, CARVALHO Jr IM \& GOULART LEA. (em preparação). Archean ultramafic mafic layered sequence of Southern São Francisco Craton (Brazil): geological and geochemistry characteristics.

CARVALHO Jr IM. 2001. Petrologia e geoquímica de rochas máficas e ultramáficas arqueanas do Cráton São Francisco Meridional: A seqüência acamada Ribeirão dos Motas. Dissertação de Mestrado. DEGEO/ EM/UFOP. 98 p.

CARVALHO Jr IM, CARNEIRO MA, SUITA MTF \& TEIXEIRA W. 1997. Anfibólio intercúmulus na Seqüência Acamadada de Ribeirão dos Motas: um modelo petrogenético para sua origem. In: Simp. Geol. Minas Gerais, IX: 1997. Ouro Preto. Anais. .. Ouro Preto: SBG. p. 38-39.

CARVALHO Jr IM, CARNEIRO MA, NALINI Jr HA \& TEIXEIRA W. 1998. Seriam as rochas da Seqüência Acamadada de Ribeirão dos Motas o correspondente plutônico do magmatismo ultramáfico do Greenstone Belt Rio das Velhas? In: Congr. Bras. Geol., 40: 1998. Belo Horizonte. Resumos. . . Belo Horizonte: SBG. p. 68.

COSTA PCC. 1999. Episódio de formação de crosta continental Arqueana no Cráton São Francisco Meridional: um exemplo a partir da região de Candeias-Campo Belo, MG. Dissertação de Mestrado. DEGEO/EM/UFOP. $132 \mathrm{p}$.

COSTA PCC, CARNEIRO MA \& NALINI Jr HA. 1998. Quartzitos da região de Candeias-Campo Belo: metassedimentos do Supergrupo Rio das Velhas ou do Supergrupo Minas? In: Congr. Bras. Geol., 40: 1998. Belo Horizonte. Resumos. . . Belo Horizonte: SBG. p. 8.

COSTA PCC, CARNEIRO MA, TEIXEIRA W, GIRARDI VAV, NALINI Jr HA, OLIVEIRA AH \& FERNANDES RA. 2006. Estudo geoquímico e petrológico dos diques máficos da Região de Candeias-Campo Belo-Santo Antônio do Amparo (MG), porção meridional do Cráton São Francisco. Geologia USP: Série Científica, 5(2): 65-84.

FAIRHEAD JD \& MAUS S. 2003. CHAMP satellite and terrestrial magnetic data help define the tectonic model for South America and resolve the lingering problem of the pre-break-up fit of the South Atlantic Ocean. The Leading Edge, 22: 779-783.

FERNANDES RA. 2001. Etapas de formação de crosta continental (do Mesoarqueano ao Mesoproterozóico) no Cráton São Francisco. Dissertação de Mestrado. DEGEO/EM/UFOP. 128 p.

FERNANDES RA \& CARNEIRO MA. 2000. O Complexo Metamórfico Campo Belo (Cráton São Francisco Meridional): unidades litodêmicas e evolução tectônica. Revista Brasileira Geociências, 30: 671-678.

FERNANDES RA, CARNEIRO MA \& TEIXEIRA W. 1997. Aspectos Petrológicos Preliminares das Rochas Granulíticas a Norte de Santana do Jacaré, MG. In: Simp. Geol. de Minas Gerais, IX: 1997. Ouro Preto. Anais. .. Ouro Preto: SBG. p. 45-46.

FERNANDES RA, CARNEIRO MA, CARVALHO Jr IM \& TEIXEIRA W. 1998. Eventos de Superimposição Metamórfica nas Rochas do Complexo Metamórfico de Campo Belo, MG. In: Congr. Bras. Geol., 40: 1998. Belo Horizonte. Resumos. . . Belo Horizonte: SBG. p. 57.

LASA ENGENHARIA E PROSPECÇÕES S.A. 2001. Relatório Final do Levantamento e Processamento dos Dados Magnetométricos e Gamaespectrométricos. Levantamento Aerogeofísico de Minas Gerais, Área 2 - Projeto Pitangui-São João del Rei-Ipatinga. Secretaria de Estado de Minas e Energia - SEME - Governo de Minas Gerais. 81 p.

MACHADO FILHO L, RIBEIRO MW, GONZALES SR, SCHENINI CA, SANTOS NETO A, PALMEIRA RCB, PIRES JL, TEIXEIRA W \& CASTRO HEF. 1983. Geologia. Folhas SF-23/24, Rio de Janeiro/Vitória. Projeto RADAMBRASIL, p. 27-304.

MINTY BRS. 1991. Simple Micro-Levelling for Aeromagnetic Data. Exploration Geophysics, 22: 591-592.

NOCE CM. 1995. Geocronologia dos eventos magmáticos, sedimentares e metamórficos na região do Quadrilátero Ferrífero, Minas Gerais. São Paulo. Tese de Doutoramento, Instituto de Geociências/USP. 127 p.

NOCE CM, TEIXEIRA W, QUÉMÉNEUR JJG, MARTINS VTS \& BOLZACHINI E. 2000. Isotope signatures of Paleoproterozoic granitoids from the southern São Francisco Craton and implications for the evolution of the Transamazonian Orogeny. Journal of South American Earth Sciences, 13: 225-239.

OLIVEIRA AH. 1999. Evolução Tectônica de um segmento crustal arqueano do Cráton São Francisco Meridional. Dissertação de Mestrado. DEGEO/EM/UFOP. 104 p.

OLIVEIRA AH. 2004. Evolução de um fragmento do Cráton São Francisco Meridional com base em aspectos estruturais, geoquímicos (rocha total) e geocronológicos (Rb-Sr, Sm-Nd, Ar-Ar, U-Pb). Tese de Doutorado. DEGEO/EM/UFOP. $136 \mathrm{p}$.

OLIVEIRA AH \& CARNEIRO MA. 1999. Petrografia do Complexo Metamórfico Campo Belo e das Unidades Supracrustais de um segmento siálico do Cráton São Francisco Meridional. In: Simp. Geol. de Minas Gerais, 10, Simp. Geol. Centro-Oeste, 7: 1999. Brasília. Anais... Brasília: SBG. p. 5.

OLIVEIRA AH \& CARNEIRO MA. 2001. Campo Belo Metamorphic Complex: Tectonic evolution of an Archean sialic crust of the southern São Francisco Craton in Minas Gerais (Brazil). Anais da Academia Brasileira de Ciências, 73(3): 397-415.

OLIVEIRA AH, CARNEIRO MA \& NALINI Jr HA. 1998a. Compartimentação litoestrutural de um segmento crustal arqueano do Cráton São Francisco Meridional. In: Congr. Bras. Geol., 40: 1998. Belo Horizonte. Resumos. . . Belo Horizonte: SBG. p. 54. 
OLIVEIRA AH, COSTA PCC, CARNEIRO MA \& NALINI Jr HA. 1998b. Feições lineares e suas implicações em um segmento crustal Arqueano do Cráton São Francisco Meridional. In: Congr. Bras. Geol., 40: 1998. Belo Horizonte. Resumos. . . Belo Horizonte: SBG. p. 58.

OLIVEIRA AH, CARNEIRO MA \& ENDO I. 1999. Evolução tectônica de um segmento crustal Arqueano do Cráton São Francisco Meridional. In: Simp. Geol. de Minas Gerais, 10, Simp. Geol. Centro-Oeste, 7: 1999. Brasília. Anais. . Brasília: SBG. p. 73.

PINESE JPP. 1997. Geoquímica, geologia isotópica e aspectos petrológicos dos diques máficos pré-cambrianos da região de Lavras (MG), porção sul do Cráton São Francisco. Tese de Doutorado. IG/USP. 178 p.

SILVA AM, PIRES ACB, MCCAFFERTY A, MORAES RAV \& XIA H, 2003. Application of airborne geophysical data to mineral exploration in the uneven exposed terrains of the Rio das Velhas Greenstone Belt. Revista Brasileira de Geociências, 33(2-suplemento): 17-28.

SWAIN CJ. 1976. Reduction-to-the-pole of regional magnetic data with variable direction, and its stabilization at low inclinations. Exploration Geophysics, 31(1-2): 78-83.

TEIXEIRA W. 1985. A Evolução geotectônica da porção meridional do Cráton do São Francisco, com base em interpretações geocronológicas. Tese de Doutorado. IG/USP. 207 pp.

TEIXEIRA W. 1993. Avaliação do acervo de dados Geocronológicos e isotópicos do Cráton do São Francisco - Implicações Tectônicas. In: Simpósio sobre o Cráton do São Francisco, II: 1993. Salvador. Anais. . . Salvador: SBG. p. 11-34

TEIXEIRA W \& CANZIAN FS. 1994. A evolução tectonotermal Proterozóica do Cráton São Francisco com base em interpretações geocronológicas K-Ar em rochas de seu embasamento. Boletim IG-USP, 25 61-80.

TEIXEIRA W, CORDANI UG, KAWASHITA K, TAYLOR PN \& VAN SCHMUS WR. 1987. Archean and Early Proterozoic crustal evolution in the southern part of the São Francisco Craton. In: International Symposium on Granite and Associated Mineralizations, 1: 1987. Salvador. Extended Abstracts... Salvador: SBG. p. 1: 37-40.
TEIXEIRA W, CARNEIRO MA, NOCE CM, MACHADO N, SATO K \& TAYLOR PN. 1996a. Pb, Sr and Nd isotope constraints on the Archean evolution of gneissic-granitoid complexes in the southern São Francisco Craton, Brazil. Precambrian Research, 78: 151-164.

TEIXEIRA W, CORDANI UG, NUTMAN AP \& SATO K. 1996b. Polyphase crustal evolution in the late Archean: The case of the Campo Belo Metamorphic Complex. In: Symp. Archean Terranes of the South American Platform, I: 1996. Brasília. Anais. . Brasília: SBG. p. 63-64.

TEIXEIRA W, ONSTOTT TC, MAKENYA M \& SZABÓ GAJ. 1997. Proterozoic thermochronology implications from ${ }^{40} \mathrm{Ar}-{ }^{39} \mathrm{Ar}$ and $\mathrm{K}$-Ar dating of the Campo Belo Metamorphic Complex, southern São Francisco Craton, Brazil. Anais da Academia Brasileira de Ciências, 69(1): 559-575.

TEIXEIRA W, CORDANI UG, NUTMAN AP \& SATO K. 1998. Polyphase Archean evolution in the Campo Belo metamorphic complex, Southern São Francisco Craton, Brazil. SHRIMP U-Pb zircon evidence. Journal of South American Earth Sciences, 11: 279-289.

TEIXEIRA W, CARNEIRO MA, QUÉMÉNEUR JJG, PINESE JP \& OLIVEIRA AH. 1999. A história policíclica (arqueana e paleoproterozóica) cinturão granulítico da parte meridional do Cráton São Francisco. In: Simp. Geol. de Minas Gerais, 10, Simp. Geol. Centro-Oeste, 7: 1999. Brasília. Anais. .. Brasília: SBG. p. 8.

TEIXEIRA W, SABATÉ P, BARBOSA J, NOCE CM \& CARNEIRO MA. 2000. Archean and Paleoproterozoic tectonic evolution of the São Francisco Craton, Brazil. In: CORDANI UG, MILANI EJ, THOMAZ FILHO A \& CAMPOS DA (Ed.). Tectonic Evolution of South America. $31^{\text {st }}$ International Geological Congress, Rio de Janeiro p. 101-137.

TEIXEIRA AA, SILVA AM, PIRES ACB, MORAES RAV \& SOUZA FILHO CR. 2006. Integração e análise de dados aerogeofísicos por meio da aplicação de técnicas de processamento digital de imagens e classificação não supervisionada: 0 exemplo do Greenstone Belt Rio das Velhas, Quadrilátero Ferrífero, MG. Revista Brasileira de Geofísica, 24(4): 559-572.

\section{NOTAS SOBRE OS AUTORES}

Maurício Antônio Carneiro é geólogo pela UFMG (1979), Mestre em Mineralogia e Petrologia (IG/USP 1985), Doutor em Geoquímica e Geotectônica (IG/USP - GEOTOP-UQÀM-McGill - 1992). Atua na área de Geociências, com ênfase em Evolução Crustal de Terrenos Arqueanos, com enfoque em Petrologia, Geoquímica, Geocronologia e Geotectônica. Atualmente é Professor Associado 1 do DEGEO/EM/UFOP, Pesquisador do CNPq nível II e membro da Sociedade Brasileira de Geologia. Até janeiro de 2008 era membro do Conselho Curador da FAPEMIG - Fundação de Amparo à Pesquisa do Estado de Minas Gerais, onde exerceu mandato por quatro anos.

Maria Sílvia Carvalho Barbosa é engenheira geóloga pela UFOP (1987), Mestre em Geologia Estrutural (DEGEO/UFOP - 1990), Doutora em Geofísica (IAG/USP - 2000). Atua na área de Geociências, com ênfase em Métodos Potenciais, Prospecção Geofísica, Tectonofísica e Perfilagem. Atualmente é Professora Adjunta 4 do DEGEO/EM/UFOP e consultora do Núcleo de Geologia do Petróleo (NUPETRO), Fundação Gorceix. É membro da Sociedade Brasileira de Geologia e da Sociedade Brasileira de Geofísica. 